\title{
Standardization of qualitative and quantitative polymerase chain reaction methods in transgenic Indica rice
}

\author{
Vibha Pandey ${ }^{1}$, K.V. Rao ${ }^{2}$, U.N. Dwivedi ${ }^{3}$, Sudhir K. Goel ${ }^{1 *}$, \\ ${ }^{1}$ CSIR- Indian Institute of Toxicology Research Lucknow, Uttar Pradesh, India \\ ${ }^{2}$ Centre for Plant Molecular Biology, Osmania University Hyderabad, Andhra Pradesh, India \\ ${ }^{3}$ Dept. of Biochemistry, Lucknow University, Lucknow Uttar Pradesh, India \\ *Corresponding author E-mail: sudhir.ji@gmail.com
}

\begin{abstract}
Rice crop gets damaged by pests and insects, and to overcome this problem globally many transgenic rice lines are being developed. Simultaneously, a need to detect and quantitate the transgene with special reference to copy number estimation also became evident. The primary objective of this study, was to successfully apply a multiplex Polymerase Chain Reaction (PCR) assay to detect the transgene- Galanthus nivalis agglutinin (GNA), Sucrose phosphate synthase (SPS) an endogenous gene, 35S-Cauliflower mosaic Virus (CaMV) as a promoter and Nopaline synthase (NOS) as terminator gene in Genetically Modified (GM) rice to differentiate from normal cultivar (NC) in a single step. Further a Sybr green based quantitative Real Time PCR (qPCR) assay was adapted to quantify the transgene (GNA) and its copy number estimation. This Sybr green based assay is economical simply utilizes specific primers for targeted genes being used in conventional PCR. The sensitivity and specificity of the protocols was also determined in terms of Limit of detection (LOD) $0.01 \%$, and Limit of quantitation (LOQ) $0.1 \%$. A dilution series of the genomic DNA from GM rice was used to generate a standard curve for relative quantification of the GNA and SPS gene. An added advantage is a quick and economical screening in early stages of GM rice lines and accurate determination of the transgene copy number in rice lines, processed foods and contaminated food products.
\end{abstract}

\section{Introduction}

Rice, one of the most important cereal crops, serves as staple food for more than two-third of the world's population and gets affected by different stress factors. Therefore, globally many transgenic rice lines are being developed. Advancement of plant biotechnology led to the development of many GM crops, in which an exogenous gene is introduced in normal cultivar (NC) to acquire the desired trait. In recent years, several GM crops have entered in the market whereas many are at the verge of commercialization all over the world. The cultivated area for GM crops throughout the world is about 148 million ha [1]. However at international level, there is no consistent and harmonized set of rules to facilitate international trade of approved GM crops and related products due to substantial differences in the laws and regulations [2].United States, Canada, Japan, Philippines, Thailand and Taiwan, a content of up to $5 \%$ food with approved GM material does not require labeling while Brazil, Australia, New Zealand and Saudi Arabia, labeling is mandatory for GM content of more than 1\% [3]. According to the European Union Regulation, the threshold limit of mixing of GMOs in NC's $0.9 \%$ per ingredient for its own approved varieties whereas $0.5 \%$ for non-approved varieties (European Commission Regulation, 1829/2003). The Government of India (DBT/GEAC) has not approved any GM food except a feed i.e., Bt cotton which was approved in 2002 [4]. Many methods have been applied in the recent years for the detection of GM content from various matrices [5, 6 and 7]. Frequently used assay i.e., nucleic acid based qualitative and quantitative (PCR and real time PCR) are applied globally for detection of GM foods [8-13]. PCR and qPCR has been a method of choice to test labeling compliance of food and feed with EU regulation 1829/2003 also. During the amplification process of quantitative real-time PCR, target DNA sequences specific for the genetic modification are amplified, detected and quantified together with DNA sequences specific for the plant taxon. The relative amounts of these sequences are calculated either on the basis of a weight/weight percentage (wt/wt \%) or on the basis of a haploid copy number ratio. 
For the unambiguous identification of an individual GMO, Annex 1 of Commission Regulation 641/2004 stipulates the use of an event-specific detection method targeting boundary DNA sequences between the plant genome and the inserted DNA. PCR and qPCR have also been selected as a detection domain as exemplified by the European Certified Reference Laboratory (CRL) (http://gmo-crl.jrc.ec.europa.eu/). Successful detection of GMO's by PCR and qPCR in durum wheat [14], rapeseed [15], potato [16] and canola [17] has been reported.

Earlier, qPCR has also been successfully used to demonstrate the copy number of transgenes in GM rice [18-20]. In the present study, we report the qualitative and quantitative protocols for the detection and quantitation of transgene GNA in GM rice line developed against sap-sucking insects [21] employing SPS as a reference gene and further confirmed the applicability for practical use by in-house validation experiment. Copy number analysis of transgene by the qPCR method will justify its utility and sensitivity and prove useful with regard to the large-scale screening of transgenic lines in the processes of risk assessment and commercialization.

\section{Material and methods}

\subsection{Rice samples}

GM rice line samples developed employing the Ti plasmid pSB11-BAR-GNA (Fig 1, Table 1) and NC variety (Chaitanya) was used in this study [21]. GM rice seeds and NC seeds were handled separately and were ground individually in laboratory grinding equipment. The ground materials were freeze dried for 24 hrs in freeze drier and stored at $-20^{\circ} \mathrm{C}$ until use.

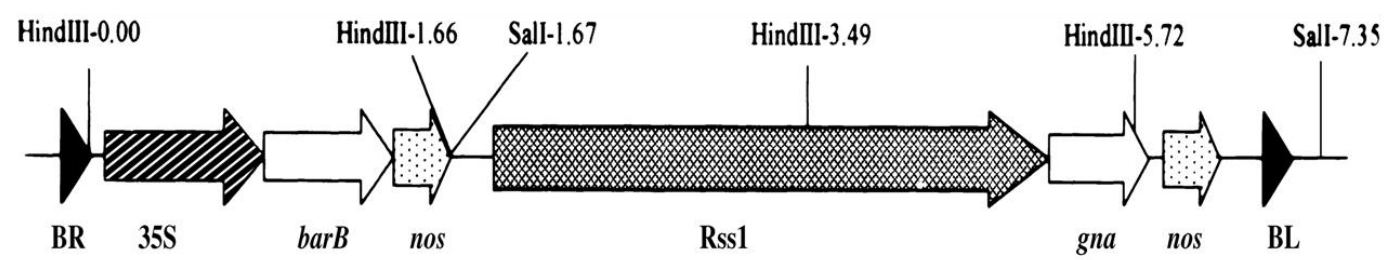

Fig-1: Construct Ti-plasmid pSB111-BAR-GNAdepicting the restriction enzyme sites inserted in Chaitanya variety

Table 1: Genes present in GM rice line

\begin{tabular}{|c|c|c|c|}
\hline Genes & Origin & Location & Reference \\
\hline GNA & $\begin{array}{l}\text { Monocotyledonous plant, galanthus nivalis } \\
\text { (snowdrop), marillidaceae family }\end{array}$ & Transgene & $\begin{array}{l}\text { Powell et } \\
\text { al.,1993 }\end{array}$ \\
\hline BAR & $\begin{array}{l}\text { Bialaphos resistance (bar) isolated from the } \\
\text { soilmicroorganism streptomyces hygroscopicusstrain } \\
\text { hp632 }\end{array}$ & Marker gene & $\begin{array}{l}\text { Shinya } \\
\text { nakamura. } \\
\text { et.al,2010 }\end{array}$ \\
\hline SPS & Sucrose Phosphate Synthase & Housekeeping gene & $\begin{array}{l}\text { M'ade et. al, } \\
2006\end{array}$ \\
\hline $\begin{array}{l}35 \mathrm{~S} \\
\text { promoter }\end{array}$ & Cauliflower mosaic virus (CaMV) & Promoter gene & Odell et al.,1985 \\
\hline NOS & $\begin{array}{l}\text { Nopaline synthase - gene derived from rhizobium } \\
\text { radiobacter }\end{array}$ & Terminator gene & $\begin{array}{l}\text { Hiroshi et } \\
\text { al.,2009 }\end{array}$ \\
\hline Rss1 & $\begin{array}{l}\text { Sucrose synthase } 1 \text { gene isolated from rice } \\
\text { corresponding to the maize sh1 locus }\end{array}$ & $\begin{array}{l}\text { promoter for GNA to } \\
\text { express in promoter region }\end{array}$ & Saha et. al, 2007 \\
\hline
\end{tabular}

\subsubsection{Preparation of the candidate reference material}

Because of lack of certified reference material (CRM) of rice, candidate reference materials (CRM's) were prepared by mixing of GM rice/NC rice seeds powder as described below. $150 \mathrm{gm}$ of GM rice Seeds and NC rice seeds were collected separately and were then crushed in a laboratory grinding equipment on an individual basis to obtain the pure dried powder. A range of candidate reference materials were prepared by mixing GM and NC seed samples on mass fractions basis i.e., $5 \%, 2 \%, 1 \%, 0.5 \%, 0.1 \%$ and $0.01 \%(\mathrm{w} / \mathrm{w})$. Preservation of all the samples was done as per the published information [22] 


\subsection{Extraction and purification of genomic DNA}

All the rice seeds (GM and NC) samples were ground in liquid Nitrogen to obtain coarsely fine powder. Genomic DNA was extracted using a silica gel membrane type kit (DNeasy plant mini kit, Qiagen, Germany). The homogenized samples $(100 \mathrm{mg})$ were incubated in buffer AP1 For $10 \mathrm{~min}$ in $2 \mathrm{ml}$ tube and $20 \mu \mathrm{l}$ of RNase A (100mg/ml) was added and mixed properly 2-3 times during incubation by vortexing the tube. After adding buffer AP2 the complete mixture was incubated on ice for 5 mins. The material was centrifuged at $4000 \mathrm{~g}$ for $10 \mathrm{mins}$ at $4{ }^{0} \mathrm{C}$ and obtained supernatant was transferred to QIA-Shredder Spin Column and further centrifuged for 5 minutes at 10,000g. The mixture so obtained was transferred in minispin column after adding 1.5 volume of buffer AP3. The column was centrifuged at $10,000 \mathrm{~g}$ for $10 \mathrm{mins}$ and flow through was discarded. After washing the column (of the bound DNA with silica membrane) with buffer AW the DNA was eluted from the column in the $100 \mu$ l of elution Buffer AE. Obtained genomic DNA was quantified by using Picodrop spectrophotometer (jkbios, UK).As per the manufactures instructions. Each sample was repeated three times to cross check the accuracy of the quantitation. DNA isolated was also analyzed on $0.8 \%$ Agarose gel (Fig 2)

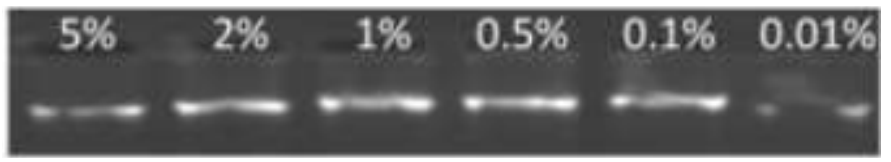

Fig 2: Agarose gel electrophoresis ( $0.8 \%)$ showing DNA isolated from candidate reference materials (CRM \%)

\subsection{Primers}

Three set of primers (forward/reverse) for each genes were designed based on the sequences of the GNA, SPS and herbicide bialaphos (BAR) genes that are present in GM rice, the gene bank accession number AF413084, U33175 and AY632421 respectively. Primers of 35 S promoter and NOS terminators were taken from the literature. Primers were designed using the online NCBI Primer blast tool and the primer designing setting were adjusted as follows; Melting Temperature $(\mathrm{Tm})=58 \pm 10 \mathrm{C}$ length of forward and reverse primer from $20-27 \mathrm{bp}$ and amplicon size 70-300 bp. (Table 2).

Table 2: Primers

\begin{tabular}{llll}
\hline Gene & Primer Sequence(5'-3') & & Amplicon Size(bp) \\
\hline & Forward & Reverse & 211 \\
GNA $^{\mathrm{a}}$ & TGGCTAAGGCAAGTCTCCT & AGGCCACCTGTGTTAGTTGC & 81 \\
SPS $^{\mathrm{a}}$ & TTGCGCCTGAACGGATAT & CGGTTGATCTTTTCGGGATG & 101 \\
$35 \mathrm{SCaMV}^{\mathrm{b}}$ & GCTCCTACAAATGCCATCA & GATAGTGGGATTGTGCGTCA & 151 \\
NOS $^{\mathrm{b}}(\mathrm{t})$ & GAATCCTGTTGCCGGTCTTG & TATCCTAGTTTGCGCCCTA & 269 \\
BAR $^{\mathrm{a}}$ & CACGTGAGCCCAGAACGA & CTCGGCCGTCCAGTCGTA & \\
\hline & & a-designed, b- published
\end{tabular}

\subsubsection{Optimization of the primers concentration for qualitative detection}

Concentration of variables as deoxynucleotide triphosphate (dNTP's), Magnesium Chloride $\left(\mathrm{MgCl}_{2}\right)$ and primers usually affect the PCR efficiency. To obtain the best PCR efficiency (i.e.90\%), annealing temperature was maintained at $58 \pm 1{ }^{\circ} \mathrm{C}$ and all the primers were optimized at this temperature for each gene. A preliminary experiment was performed to optimize the appropriate primer set along with accurate concentrations from different sets of designed and available primers for all the genes. Best primers having specificity at $58^{\circ} \mathrm{C}$ in singleplex and in multiplex as well were selected for the study. BAR gene was showing nonspecific binding when qualitative assay was performed in multiplex, further studies were performed without BAR gene. Multiplex detection was performed only with promoter and terminator sequences and reference gene. The set of primer sorted out giving appropriate results in multiplex detection were also used for the qPCR analysis.

\subsection{Conventional PCR conditions for qualitative detection}

For the monoplex qualitative detection of all the genes present in gene construct of GM rice, PCR was carried out in 20 $\mu \mathrm{l}$ reaction volume on a PTC-100 thermocycler machine (MJ Research Waltham, MA). Each reaction mixture contained $2 \mu \mathrm{l}$ of $10 \mathrm{X}$ PCR buffer (10mM 169 Tris-HCl, pH8.3, 50mM KCl), $1.5 \mu l$ of $1.5 \mathrm{mM} \mathrm{MgCl} 2,2 \mu \mathrm{l}$ of $200 \mu \mathrm{M}$ each dNTP's, $0.25 \mathrm{U}$ of Taq DNA Polymerase, $1 \mu \mathrm{l}$ of $10 \mu \mathrm{mol}$ of each primer forward (F) and reverse (R) and $1 \mu \mathrm{l}$ of template DNA corresponding to 50ng. Qualitative PCR amplification programs was as follows: an initial denaturation step for $10 \mathrm{~min}$ at $95^{\circ} \mathrm{C}$, followed by 35 cycles of $30 \mathrm{~s}$ at $94^{\circ} \mathrm{C}, 30 \mathrm{~s}$ at $58^{\circ} \mathrm{C}$ and $30 \mathrm{~s}$ at $72^{\circ} \mathrm{C}$ with a final elongation step of $5 \mathrm{~min}$ at $72^{\circ} \mathrm{C}$. 


\subsubsection{Multiplex PCR detection}

PCR programme for multiplex PCR was same as of mono plex PCR, each reaction mixture contained $2 \mu 1$ of 10x PCR buffer (10mM Tris- $\mathrm{HCl}$, pH 8.3, 50mM KCl), $1.5 \mu \mathrm{l}$ of $1.5 \mathrm{mM} \mathrm{MgCl}_{2}, 2 \mu \mathrm{l}$ of $200 \mu \mathrm{M}$ each dNTP's, $0.25 \mathrm{U}$ of Taq DNA Polymerase, $1.5 \mu \mathrm{l}$ of $10 \mu \mathrm{M} \mathrm{F} / \mathrm{R}$ primers for GNA gene, and $1 \mu \mathrm{l}$ of $10 \mu \mathrm{M}$ F/R primer of SPS gene for duplex detection of transgene (GNA) and reference gene (SPS), further $1.5 \mu \mathrm{l}$ of $10 \mu \mathrm{M} \mathrm{F} / \mathrm{R}$ primer for GNA gene and $1.25 \mu \mathrm{l}$ of $10 \mu \mathrm{M} \mathrm{F} / \mathrm{R}$ primers for NOS terminator gene and finally for triplex detection of $35 \mathrm{~S}$ promoter, NOS (t) and GNA 1.0 $\mu \mathrm{l}$ of $10 \mu \mathrm{M} \mathrm{F} / \mathrm{R}$ primer, $1.5 \mu \mathrm{l}$ of $10 \mu \mathrm{M} \mathrm{F} / \mathrm{R}$ primer and $1.75 \mu \mathrm{l}$ of $10 \mu \mathrm{M}$ F/R primer respectively were used along with the 60 ng template DNA.

\subsection{Analysis of PCR product}

PCR products were analyzed on $1.5 \%(\mathrm{w} / \mathrm{v})$ agarose by gel electrophoresis and stained with $0.5 \mu \mathrm{g} / \mathrm{ml}$ ethedium bromide (Sigma-aldrich, USA). $5.0 \mu \mathrm{l}$ of PCR product was electrophoresed at a constant voltage (50V) for 60 mins in 1X Tris Acetate (TAE) buffer.After electrophoresis the gel was viewed under UV light in GelDoc-1000 (Bio-Rad, USA).

\subsection{Sequencing of amplified product}

PCR products of target gene GNA, SPS, NOS (t) and 35S Promoter were purified using QIaquick PCR purification kit (Qiagen, USA) and sequencing was performed by dideoxy sequencing methods. Obtained sequence data was analyzed with the help of Chromas software and further analyzed by searching in gene bank sequence database using the computer algorithm, BLAST-2 a tool of NCBI.

\subsection{Quantitative PCR}

qPCR assays were performed using the Stratagene Max3000p instrument. All reactions were run in triplicates in 96 well plates. The $20 \mu \mathrm{l}$ reaction mixtures contained $10.0 \mu \mathrm{l} 2 \mathrm{X}$ Taq SYBR premix Ex Taq (Takara Japan), $1 \mu \mathrm{l}$ of each forward and reverse primer of $10 \mu \mathrm{M}$ concentration and $1 \mu \mathrm{l}$ of template DNA. The reaction conditions were as follows: Initiation step for $30 \mathrm{~s}$ at $95^{\circ} \mathrm{C}$ followed by 40 cycles of $15 \mathrm{~s}$ at $95^{\circ} \mathrm{C}$ and $30 \mathrm{~s}$ at $58^{\circ} \mathrm{C}$ and $72^{\circ} \mathrm{C}$ for $15 \mathrm{~s}$, and dissociation curve was obtained by increasing the melting temperature at specific rate from $55^{0} \mathrm{C}$ to $95^{0} \mathrm{C}$ at a specific rate at 0.1 or $0.4 \mathrm{c} / \mathrm{s}$. To generate a standard curve for the endogenous gene SPS and exogenous gene GNA genomic DNA from transgenic line was used as described by Mason, et al [23]. Standard curves were calibrated using six concentrations of the genomic DNA of the taken transgenic line, i.e. 50, 5.0, 0.5, 0.05, 0.005 and $0.0025 \mathrm{ng} /$ reaction. These standard curves were used for the relative quantitation of the GNA and SPS gene. A Non template control (NTC) was also prepared as a negative control for the data analysis.

\section{Theory and calculation}

\subsection{Copy number estimation by qPCR and statistical analysis}

To calculate the transgene copy numbers, we used comparative $\mathrm{Ct}$ value method defined as relative method, which combined two quantifications; one is of exogenous gene and another of endogenous gene [18, 19and 24]. From the previously described methods we compared the quantitative results obtained for transgene, GNA with reference gene SPS. For both the genes standard curves were obtained and starting quantities of each gene in selected rice line samples was determined from the respective standard curves. Further, rline was calculated by dividing the amount of endogenous gene from the amount of transgene. These values were compared to the experimentally determined levels in each transgenic rice sample (100\% GM rice and CRM's). In order to validate our results we followed the calculation method described by Mason et al [23] which is as follows:

Using the generated standard curve to determine the starting quantities for GNA and SPS gene

The ratio rline was calculated:

$$
\text { rline }=\text { SQGNA } / \text { SQSPS }
$$

$\mathrm{SQ}$ is the starting quantities. The uncertainty ( $\Delta$ rline) was derived from the following equation: 
A transgenic rice line whose copy number is known to be one should be used as a calibrator [25], therefore, the copy number for other samples would be determined as rline /rcal. Since such a transgenic line was not available in our case, we used the virtual calibrator as described by Mason et al. in which all the available samples were considered. The main idea is to find a value called $\mathrm{r} 1$ corresponding to copy number one, then this value will be used instead of rcal in determining the copy numbers of the transgenic lines. To determine the value of $\mathrm{r} 1$ the following equation was applied:

$\mathrm{F}(\mathrm{r} 1)=\Delta$ lines $[\mathrm{rline} / \mathrm{r} 1-\mathrm{N}($ rline $/ \mathrm{r} 1)] 2 /(\Delta \mathrm{rline}) 2$

Where $\mathrm{N}$ (rline /r1) is the nearest integer of rline $/ \mathrm{r} 1$

R1 value in the present study is 0.32 for the GNA and 0.26 for the SPS gene. Once the r1 has been determined, the copy number for each line is determined as rline/r1.

\subsection{Examination of analytical performance by serial dilution}

In order to examine the limit of detection (LOD) and limit of quantitiation (LOQ) of the developed method by PCR and qPCR, several independent serial DNA dilution series were tested and ranged from 50,000pg $/ \mu 1$ to $2.5 \mathrm{pg} / \mu \mathrm{l}$. We prepared six dilution series (1:10 factor) of extracted GM rice DNA solution(s) by, DNA from 100\% GM rice and CRM's ranging from $5 \%, 2 \%, 1 \%, 0.5 \%, 0.1 \%$ and $0.01 \%(\mathrm{v} / \mathrm{v})$ diluted with $\mathrm{NC}$ rice DNA solution. The lowest level of dilution was 1:5 (v/v), expected to contain about 5-10 copies of rice genome haploid per sample, according to the Cvalue of rice [26]. Each dilution series was prepared with two independent replications for use in the examination.

\section{Results and discussion}

\subsection{Detection of GM rice by PCR}

The primary aim of the present study was to develop a qualitative detection based multiplex PCR method to screen the GM crop and also to find out the limit of detection (LOD) of the transgene in GM rice. Thus, a fast and efficient screening method for detection of transgene along with reference gene, promoter and terminator in the transgenic rice has been established. By monoplex PCR, PCR fragments of $81 \mathrm{bp}, 101 \mathrm{bp}, 151 \mathrm{bp}, 211 \mathrm{bp}$ and $269 \mathrm{bp}$ were amplified with gene specific primers of SPS, 35S Promoter, NOS terminator, GNA and BAR genes respectively (fig not shown). A step ahead transgene (GNA), 211 bp and housekeeping gene (SPS) 81 bp are simultaneously amplified by duplex PCR, in GM rice line and in-house made different CRM's (fig $3 \mathrm{a}, \mathrm{b}$ ). After corroboration of both the genes another duplex detection was targeted with transgene (GNA) and terminator (NOS). $211 \mathrm{bp}$ fragment of transgene (GNA) and $151 \mathrm{bp}$ fragment of terminator (NOS) were amplified in transgenic rice line (Fig 3c).Similarly, in multiplex PCR targeting GNA, SPS, 35S promoter amplifying fragments of $211 \mathrm{bp}, 81 \mathrm{bp}$ and $101 \mathrm{bp}$ were found respectively (Fig 3d). Approach towards duplex/multiplex detection targeting transgene along with reference gene, promoter and terminator will be a better possibility to screen those GM crops having SPS as a endogenous gene with an assumption of lectin gene incorporation as a transgene. In contrast as expected non transgenic rice line showed no amplification signals of GNA, CaMV-35S promoter and NOS terminator but a strong presence of SPS gene. The presence of GNA gene product in duplex as well as multiplex substantiates the authenticity and sensitivity of the method used to detect the ransgenes in rice genome. Most PCR protocols for GMO detection involve reactions that amplify a single target [5]. The combination of several primer pairs in the same reaction tube will lead to more efficient, faster, cost effective and comparative evaluation of results as compared to monoplex PCR [27].

\subsection{Transgene copy number estimation by qPCR in GM rice}

In this method, the amplification of the transgene of interest, GNA was compared with that of an endogenous SPS gene. The two genes had different dissociation curve. By amplifying both genes on same conditions we achieved identical conditions. DNA was prepared from the GM as well as NC samples. Three replicates of the samples from each transgenic sample were subjected to qPCR reaction to correct the pipetting error; the values were averaged to calculate the copy number. Standard curves were obtained from serial dilution of a transgenic line. The correlation coefficients of the standard curves were 0.931 and 0.988 for the endogenous SPS and the transgene GNA, respectively (Figs 4 a, b). With the ability to measure the PCR products as they accumulate, it is possible to measure the amount of PCR product when the reaction is in the exponential phase. During this exponential phase of the PCR reaction it is possible to extrapolate back to determine the starting amount of template. These values were given with a $95 \%$ confidence interval and used to calculate the copy number of the transgene in each transgenic rice sample, the obtained results for GNA and SPS gene were combined and shown in table 3. 

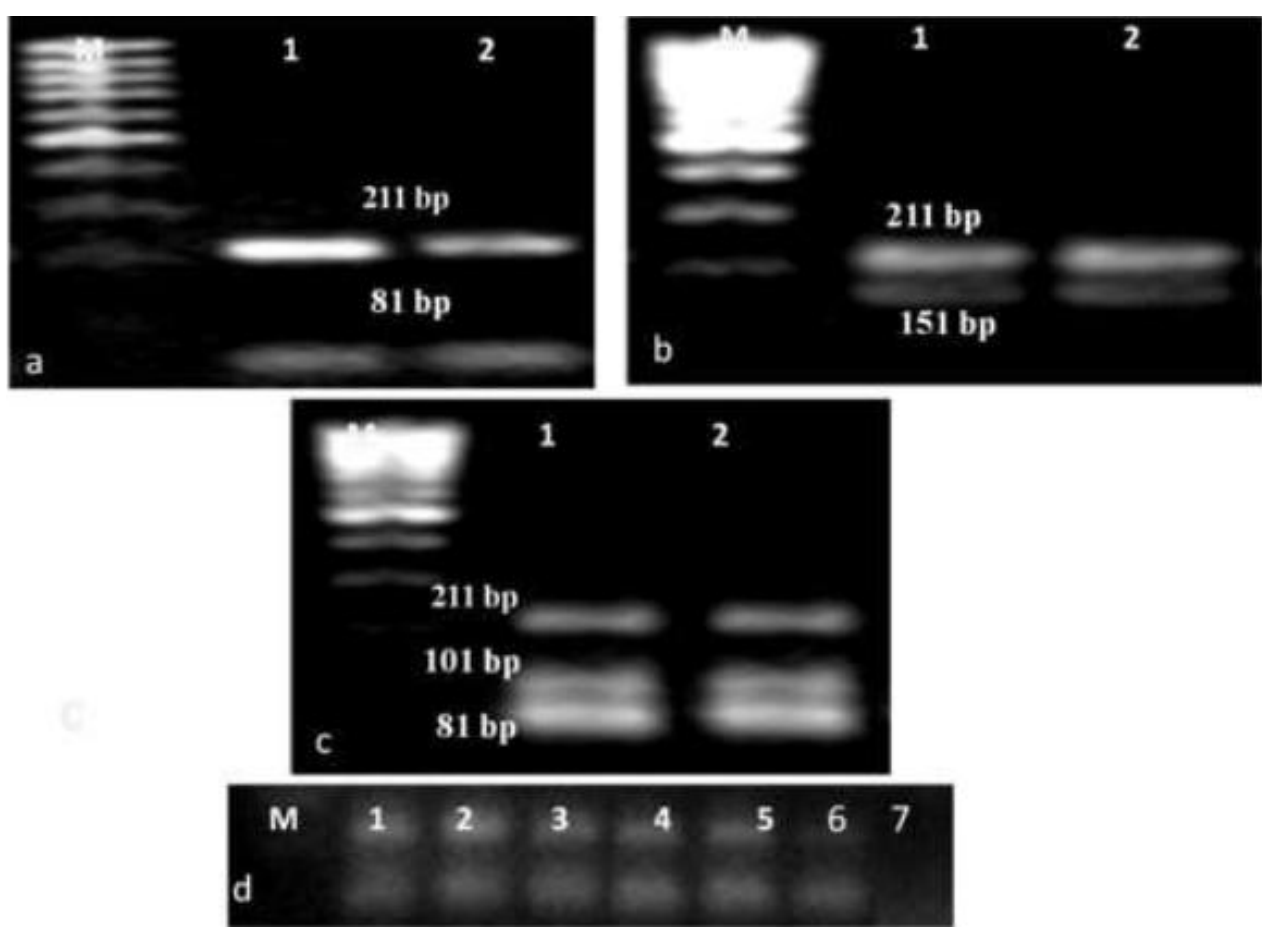

Fig.3: Agarose Gel Electrophoresis (1.5\%) showing duplex/multipex PCR detection in transgenic rice line. Duplex PCR products amplified with (a)GNA(211bp) and SPS(81bp), (b)GNA(211bp) and NOS(t)(151 bp),(c) GNA(211bp)35SPromoter(101bp) and SPS (81bp) (a-d)M-80 bp DNA ladder (a-c) Lane 1- To generation \& Lane 2- $\mathrm{T}_{8}$ generation. (d) Duplex detection of GNA(211bp) and SPS(81bp) in Candidate Reference Material's Lane1-7: $5 \%, 2 \%, 1 \%, 0.5 \%, 0.1 \%, 0.01 \%$ and Non Template Control.

Table 3: Reproducibility of transgene and endogenous gene Ct values using DNA isolated from standard rice by quantitative Real-Time PCR

\begin{tabular}{|c|c|c|c|}
\hline & DNA amount $(\mathrm{pg})$ & Ct value \pm SD (GNA) & Ct value \pm SD (SPS) \\
\hline STD1 & 50,000 & $19.3166 \pm 0.5398$ & $17.1033 \pm 0.1703$ \\
\hline STD2 & 5000 & $23.1633 \pm 0.0709$ & $23.4166 \pm 0.1607$ \\
\hline STD3 & 500 & $26.2000 \pm 0.2645$ & $26.5700 \pm 0.4942$ \\
\hline STD4 & 50 & $29.2433 \pm 0.1021$ & $28.4433 \pm 0.4942$ \\
\hline STD5 & 5 & $31.8966 \pm 0.0057$ & $29.7433 \pm 0.0642$ \\
\hline STD6 & 2.5 & $33.4633 \pm 0.3636$ & \\
\hline
\end{tabular}

Mean of three $\mathrm{Ct}$ values \pm standard deviation

The copy numbers of GNA gene were determined by comparing the absolutely quantified GNA transcripts with those of the endogenous SPS gene in terms of the standard curves. To estimate the number of transgene copies in the transgenic plants, the ratio between transgene and Endogenous gene (rline) was calculated (Table 4). Using the rline values the virtual calibrator ( 1 1) was calculated. The virtual calibrator is the value which corresponds to one copy of the transgene [23]. The $\mathrm{r} 1$ value in this study was 0.31 for the transgene GNA. The copy number for each sample was determined as rline/r1 (Table 4). Seven transgenic rice samples were tested, and the results indicated that in six samples the calculated copy number were 3 , in one sample the estimated copy number is 1 , whereas 0 copy number were estimated in NC (Table 4).

Table 4: Copy number estimation of transgene

\begin{tabular}{|c|c|c|c|c|}
\hline $\mathrm{SQ}_{\text {(SPS) }}$ & $\mathrm{SQ}_{(\mathrm{GNA})}$ & $r_{\text {line }}=\mathrm{SQ}_{\mathrm{GNA}} / \mathrm{SQ}$ sPS & $\mathrm{r}_{\text {line }} / \mathrm{r}_{1}$ & Copy no \\
\hline 76.11 & 074.01 & 1.001 & 3.229 & 3 \\
\hline 101.07 & 107.03 & 0.940 & 3.032 & 3 \\
\hline 115.00 & 124.16 & 0.926 & 2.987 & 3 \\
\hline 92.91 & 100.09 & 0.928 & 2.993 & 3 \\
\hline 115.08 & 117.41 & 0.982 & 3.160 & 3 \\
\hline 301.01 & 340.61 & 0.888 & 2.860 & 3 \\
\hline 20.05 & 133.50 & 0.150 & 0.483 & 1 \\
\hline
\end{tabular}



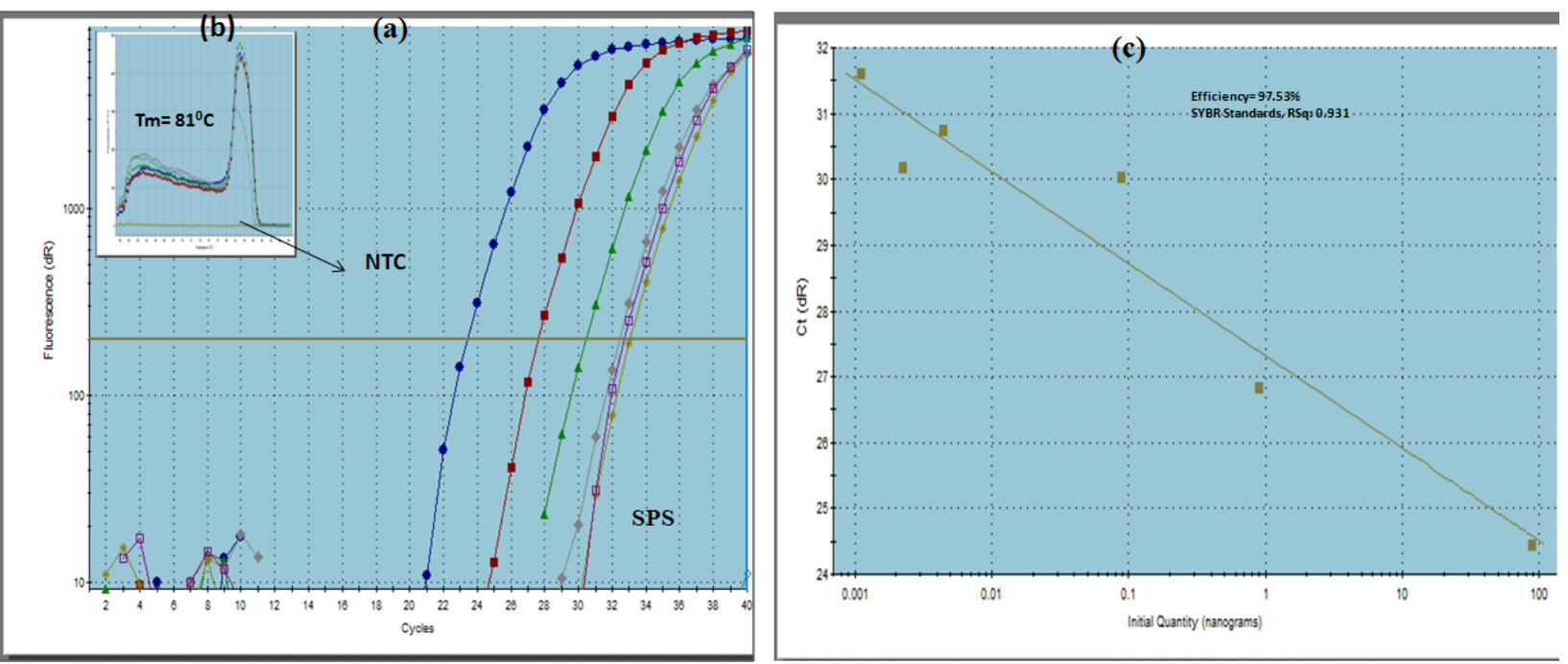

Fig.4: (I) Real-time PCR amplification and standard curve of SPS, endogenous gene.(a)Real-time PCR logarithmic plot tenfold serial dilutions of a rice standard DNA.(b) melting curve( $\mathrm{Tm})=81^{\circ} \mathrm{C}$ and no peak in Non-Template Control (c) standard curve showing correlation Coefficient and slope (plotted Ct values versus the log of quantity)
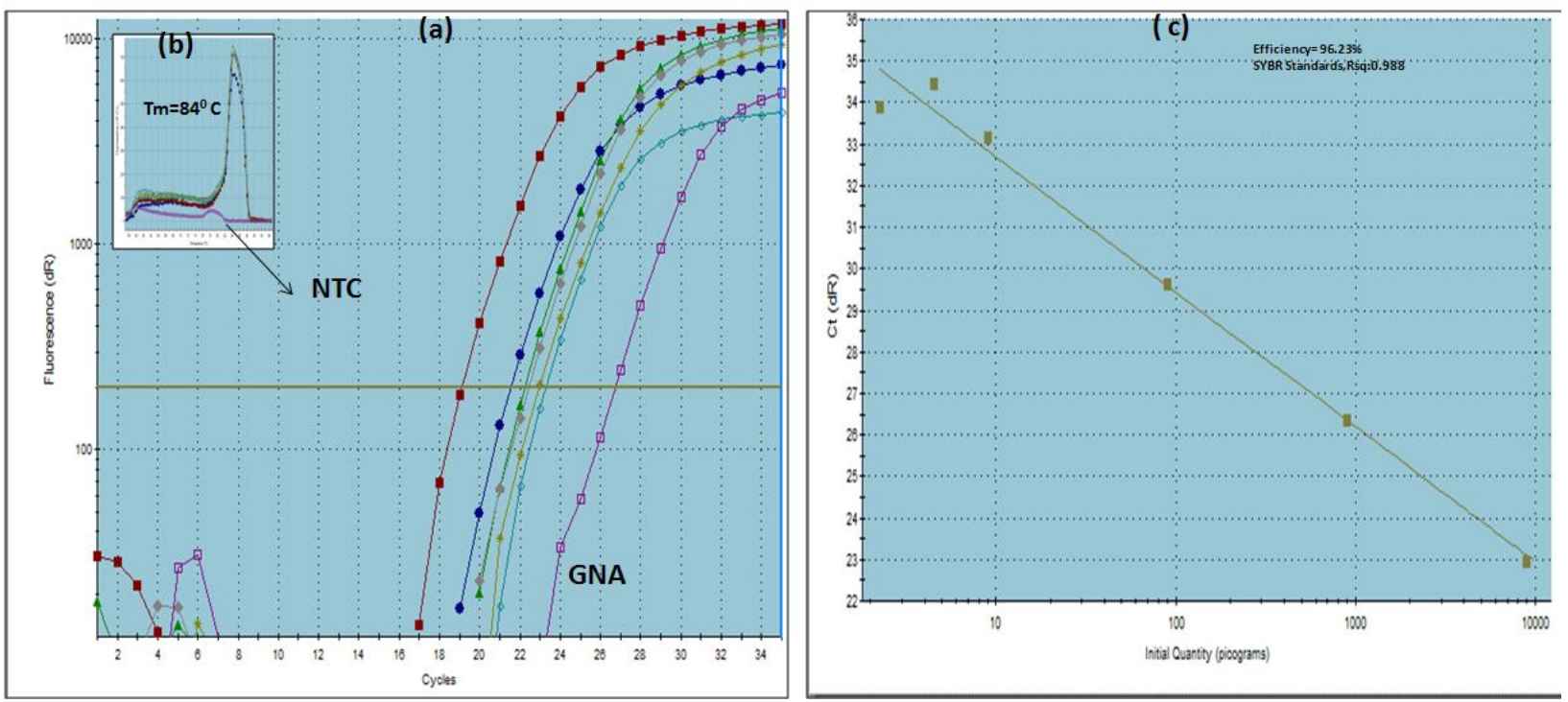

Fig.4: (II) Real-time PCR amplification and standard curve for GNA, Transgene (a)Real time PCR logarithmic plot tenfold serial dilutions of rice standard DNA(b)melting curve $(\mathrm{Tm})=84^{\circ} \mathrm{C}$ with no peak in Non-Template Control (c) Standard curve showing correlation Coefficient and slope (plotted Ct values versus the log of quantity)

\subsection{Validation of the standard curves and PCR efficiency}

For any quantitative assay, the establishment of a standard curve is one of the key steps in determining the copy number of the transgene. Ideally, a standard curve should be established using one transgenic line in which the copy number had been previously determined by Southern blot analysis. In our case, such a transgenic line was not available. Therefore, transgene copy number estimations were made in relation to standardized curves obtained from qPCR analysis of serial standard DNA dilutions of the SPS and GNA genes. Before using the relative quantitative method to estimate the transgene copy numbers, we needed to validate the curves and demonstrate that the endogenous and transgene amplifications occur at approximately equal efficiencies. Serial dilutions of genomic DNA from one transgenic sample were assayed in qPCR reactions. By plotting the common logarithm of dilution series of DNA (50, 5.0, 0.5, 0.05, 0.005 and $0.0025 \mathrm{ng} /$ reaction) against the $\mathrm{Ct}$ values of these dilutions, the efficiency was calculated. These efficiencies were $\mathbf{9 7 . 5 3 \%}$ for endogenous gene and $96.23 \%$ for transgene in the Standard dilutions, indicating high efficiency for both reactions. The ideal slope should be 3.32 for $100 \%$ PCR efficiency [28]. The PCR efficiencies obtained in this study were adequately functional and accurate to calculate the starting amount of the unknown samples. To further validate the quantification accuracy, the standard curve was generated three times. As shown in Table 3, the reproducibility of 
this qPCR system was estimated with six rice DNA dilutions, 50,000, 5,000, 500, 50, 5 and 2.5 picogram. The Ct values ranged from 17.1033 to 29.7433 the standard deviation (SD) values ranged from 0.1703 to 0.0642 for the endogenous gene (Table 3). These values for the transgene were 19.3166 to 33.4633 and SD from 0.5398 to 3180.3636 The SD values from these tests were relatively small, indicating that the qPCR assay was stable and reliable.

\subsection{Reproducibility of the assay}

To further validate the accuracy and stability of our quantification protocol, we also generated and compared two separate standard curves for promoter and terminator genes. We found that the coefficient variation (CV) values for the promoter and terminator gene varied from $2.01 \%$ to $2.15 \%$ and that the standard deviation (SD) values were between 0.07 and 0.78 (Table 5). These data showed that the CV and SD values varied only slightly across the experiments, indicating that the qPCR systems functioned stably and reliably.

Table 5: Reproducibility of $35 \mathrm{~S}$ promoter and NOS terminator genes.

Ct values obtained by quantitative Real-Time PCR using DNA isolated from standard rice

\begin{tabular}{lccc}
\hline \multicolumn{3}{c}{ Ct values obtained by quantitative Real-Time PCR using DNA isolated from standard rice } \\
\multicolumn{3}{c}{$(\mathrm{pg})$} & \multicolumn{3}{c}{ Ct Value \pm SD } \\
\hline STD1 & 50,000 & $19.1122 \pm 0.1852$ & $18.1177 \pm 0.1595$ \\
STD2 & 5000 & $22.2654 \pm 0.2396$ & $21.2950 \pm 0.0703$ \\
STD3 & 500 & $25.3603 \pm 0.1764$ & $24.1532 \pm 0.2024$ \\
STD4 & 50 & $27.8040 \pm 0.7586$ & $27.3490 \pm 0.2288$ \\
STD5 & 5 & $30.8124 \pm 0.7771$ & $30.6900 \pm 0.0659$ \\
STD6 & 2.5 & $32.7917 \pm .1205$ & $32.2940 \pm 0.4090$ \\
\hline
\end{tabular}

\subsection{Role of dissociation curve in identifying the amplified product}

In this study we suggest the use of a fluorescent nucleic acid dye such as SYBR green together with an analysis of amplification plots and melt curves to optimize assays. In few decades researchers started using probe for specific binding and specific product amplification but without specific probe melt curves are a powerful means of providing accurate identification of amplified products and distinguishing them from primer-dimer and other small amplification artifacts. DNA melts at a characteristic temperature called the melting temperature (Tm), defined as the temperature where half of the DNA helical structure is lost. The melting temperature of a DNA molecule depends on both its size and its nucleotide composition. During melt curve analysis, the real-time machine continuously monitors the fluorescence of each sample as it is slowly heated from a user defined temperature below the Tm of the products to a temperature above their melting point. Then after melting peaks are calculated by taking the differential (the first negative derivative $(-\mathrm{dF} / \mathrm{dT})$ of the melt curve. Tm parameters seems to be a good tool to discriminate between PCR products of various GMO's provided one make sure to use same kit [29]. These peaks are analogous to the bands on an electrophoresis gel and allow for the qualitative monitoring of products at the end of a run. Short primer dimers will melt at lower temperature than longer, target amplicon products. In present study Tm for the GNA and SPS genes are $840 \mathrm{C}$ and $810 \mathrm{C}$ respectively whereas NTC showing no dissociation peak /Tm.

\subsection{Limit of detection and limit of quantification}

The limit of detection (LOD) and limit of quantification (LOQ) refer to the lowest quantity of the target that can reliably be detected and quantified with a probability of higher than 95\%. In order to achieve the LOD and LOQ of PCR and qPCR assay, Seed powder of GM rice were mixed with seed powder of NC rice at $5 \%, 2 \%, 1 \%, 0.5 \%, 0.1 \%$, and $0.01 \%(\mathrm{w} / \mathrm{w})$, the DNA preparation and PCR reaction were performed by the above described procedure in materials and methods. Each sample was run in triplicate. The LOD is defined in terms of that transgenic sample (wt/wt) in which we could detect the transgene. In this study the obtained LOD is $0.01 \%$ and the obtained LOQ is $0.1 \%$. Not to get confuse with the primer/dimer we always run a negative Control either in PCR or in qPCR. Shao. et al [22] determined the limit of quantification to be $0.1 \%$ in Chinese GM rice relative to the rice content. However, for the detection of transgenic rice line Jeong et al [20] reported that the absolute LOD was between 7.82 and 1.96 copies of TPSP and the absolute LOQ was between 31.26 and7.82 copies. The described method has been optimized for the category of food samples analyzed in our laboratory. The method is more suitable to screen the GM crops as most of the transgenic lines usually possess the $35 \mathrm{~S}$ promoter and NOS as terminator sequences in another stream SPS is being used in many of the transgenic rice lines as a reference gene so multiplex detection with promoter and Transgene will be an authentic approach towards cost and time saving, thus the developed protocol may be a step ahead to detect/quantitate the transgenes in GM crops. 


\section{Conclusion}

Multiplex PCR will be a time saving and reliable approach to screen those GM crops having GNA, 35S promoter and NOS terminator as well as for those GM crops in which SPS has been used as a reference gene. The results obtained from qPCR for quantifying transgene copy number were highly concordant. In addition, the high sensitivity and efficiency of qPCR allowed us to analyze more samples and quantify the transgene copy number more quickly and accurately. In rice plant this assay has significant application in genetic engineering and tissue culture for expediting the identification of transgenic tissue and selecting transformation events with a low copy number of the transgene at much earlier stages of transgenic plant development Than Southern blot analysis. The prompt identification of low copy number lines would expedite plant transformation and breeding projects, especially those for food plants which are season dependent in qPCR, there is no post-PCR analysis of samples, thereby minimizing handling time and lessening the likelihood of contamination that may lead to false positive results. Thus, it is important to screen the transgenic samples at an early stage to distinguish them with low copy number from those with high copy number. qPCR provides a fast and reliable method.

\section{Abbreviations}

CRM-Candidate Reference Material, NC-Normal Cultivar, DBT-Department of Biotechnology, GEAC- Genetic Engineering Approval Committee

\section{Acknowledgements}

The authors are grateful to Dr. K. C. Gupta Director, IITR, Lucknow for his support throughout the study. Fellowship to V P from Indian Council of Medical Research (ICMR) is thankfully acknowledged. The author thanks to Dr. L.K.S Chauhan for critical evaluation of the manuscript. IITR communication number is 2961.This work was supported by Department of Biotechnology (DBT), New Delhi India and Ministry of Health and Fmily Welfare (MOHFW).

\section{References}

[1] James, C. Executive summary of global status of commercialized biotech/GM crops. ISAAA Briefs 37. (2007)

[2] Premanandh, J. Global consensus-need of the hour for genetically modified organisms (GMO) labeling. Journal of Commercial Biotechnology, 17, (2010). 37-44.

[3] Gruere, G.P. \& Rao, S. RA review of international labeling policies of genetically modified food to evaluate India's proposed rule. AgBio Forum, 10, (2007)51-64

[4] Mangal, M., Malik, K., \& Randhawa, G.J. Import of transgenic planting material.National scenario. Current Science, 4, (2003) 454 -458.

[5] Lipp, M., Anklam, E., \& Stave, J. W. Validation of an immunoassay for detection andquantitation of a genetically modified soyabean in food and food fractions using reference materials: inter laboratory study. Journal of AOAC International, 83, (2000) 919-927

[6] Rogan, G. J., Dudin, Y. A., Lee, T. C., Magin, K. M., Astwood, J. D., Bhakta, N. S., et al.Immunodiagnostic methods for detection of 5enolpyruvylshikimate-3-phosphate synthase in Round Ready soybeans. Journal of Food Control, 10, (1999) 407-414

[7] Stave, J. W., Magin, K., Schimmel, H., Lawruk, T. S., Wehling, P., \& Bridges, A. AACCcollaborative study of a protein method for the detection of genetically corn. Cereal Foods World, 45, (2000) 497-501.

[8] Vollenhofer, S., Burg, K., Schmid, J., Kroath, H. genetically modified organisms in food screening and specific detection by polymerase chain reaction. J Agric Food Chem, 47, (1999) 5038-5043.

[9] Matsuoka, T., Kawashima, Y., Akiyama, H., Miura, H., Goda, Y., Kusakabe, Y., Isshiki, K., Toyoda, M., Hino. A. A method of detecting recombinant DNAs from four lines of genetically modified maize. J Food Hyg Soc Jpn, 41, (2000) 137-143.

[10] Matsuoka, T., Hideo, K., Akiyama, H., Miura, H., Goda, 459 Y., Kusakabe, Y., Isshiki, K., Toyoda, M., Hino, A. A multiplex PCR method of detecting recombinant DNAs from five lines of genetically modified maize. J Food Hyg Soc Jpn. 42, 1, (2001) 24-32

[11] Hernandez, M., Rodriguez-Lazaro, D., Zhang, D., Esteve, T., Pla, M., Prat, S., Interlaboratory transfer of a PCR multiplex method for simultaneous detection of four genetically modified maize lines Bt11 MON810 T25 and GA21 J Agric Food Chem, 53, (2005) 3333-3337.

[12] Lee, S.H., Min, D.M., Kim, J., K. (2006) Qualitative and quantitative polymerase chain reaction analysis for genetically modified maize MON863 J Agric Food Chem, 54, 1124-1129.

[13] Vaitilingom, M., Pijnenburg, H., Gendre, F., Brignon, P. (1999) Real-Time PCR quantitative PCR detection of genetically modified Maximizer maize and Roundup Ready soybean in some representative foods. J Agric Food Chem, 47, 5261-5266.

[14] 14. Terzi, V., Ferrari, B., Finocchiaro, F., Fonzo, N.D., 490 Stanca, A.M., Lamacchia, C. (2003) TaqMan PCR for detection of genetically modified durum wheat J Cereal Sci, 37,157-163

[15] Chen, H., Wu, Y.H., Song, D.Y., Zhang, W. Dong X.Y., Li PW, On-line preconcentration and UV determination of DNA fragments by dynamic coating capillary electrophoresis and its application to detection of genetically modified oilseed rape based on PCR. Microchem J, (2007)17-22. 
[16] Malliga, M., Nagarajan \& Solke H.D.B. an oligonucleotide array to detect genetically modified events in potato. Plant Mol Biol Rep, 21, (2003) 259-270.

[17] Demeke, T., Ratnayaka, I Multiplex qualitative PCR assay for identification of genetically modified canola events and real-time event-specific PCR assay for quantification of the GT73canola event. Food Control, 19, (2008) 893-897.

[18] Ding, J., Jia, J., Yang, L., Wen, H., Zhang, C., Liu, W Validation of a rice specific gene, sucrose phosphate synthase, used as the endogenous reference gene for qualitative and real-time quantitative PCR detection of transgenes. J Agric Food Chem, 52, (2004) 3372-3377.

[19] Yang, L.T., Ding, J.Y., Zhang, C.M., Jia, J.W., Weng, H.B., Liu, W.X. Estimating the copynumber of transgenes in transformed rice by realtime quantitative PCR. Plant Cell Rep 23, (2005) 759-763.

[20] Jeong, S.C., Pack, I.S., Cho, E.Y., Youk, E.S., Park, S., Yoon, W.K. Molecular analysis and quantitative detection of a transgenic rice line expressing a bifunctional fusion TPSP. Food Control, 18, (2007) 1434-1442.

[21] Nagadhara, D., Ramesh, S., Pasalu, I.C., Kondala, Rao.Y., Krishnaiah, N.V., Sarma, N.P., Bown, D.P.,Gatehouse, J.A., Reddy, V.D., Rao, K.V. Transgenic indica rice resistant to sap sucking insects Plant Biotechnology Journal, (2003) 231-240.

[22] Shao-bin, Gu, Ying. Wu.,Shi-Chang, Li., LiLi, Jian-bo, Yang. Development of a real483 time multiplex PCR system for the quantitative detection of Chinese GM rice. Sci Food Agric, 89, (2009) 1101-1106.

[23] Mason,G., Provero, P., Vaira, A.M., Accotto, G.P. Estimating the number of integrationsin transformed plants by quantitative real-time PCR. BMC Biotechnol, 2, (2002) 20-30.

[24] Schmidt, M. A., Parrott, W.A Quantitative detection of transgenes in soybean Glycinemax (L.) Merrill and peanut (Arachis hypogaea L.) by real-time polymerase chain reaction. Plant Cell Rep, 20, (2001)422-428.

[25] Ingham, D. J., Beer, S., Money, S., Hansen, G. Quantitative real-time PCR assay fordetermining transgene copy number in transformed plants. Biotechniques, 31, (2001) 132-140.

[26] The Plant Cell, 14, 521, March (2002). www.plantcell.org.

[27] James, D., Schmidt AM, Wall E, Green M, Masri, S. Reliable Detection and identification of Genetically Modified Maize, Soybean, and Canola by Multiplex PCR Analysis.

[28] J Agric Food Chem, 51, (2003) 5829-5834 Ginzinger, D.G Gene quantification using real-time quantitative PCR an emergingtechnology hits the mainstream. Exp Hematol, 30, (2002).503-512.

[29] Goel, S.K., Tewari, S., lal, H., Mishra, P., Agarwal, S.K., Dwivedi, U.N., Kumar, M SYBR Green I chemistry based Real time PCR: Melting curve discrepancies. Current Trends in Biotechnology and Pharmacy. 2, (2008) 555 -561. 